\title{
Percepções de indivíduos acerca do uso da bicicleta como modo de transporte
}

\author{
Janice Kirner Providelo'; Suely da Penha Sanches ${ }^{2}$
}

\begin{abstract}
Resumo: O objetivo desse artigo é investigar as percepções de indivíduos acerca do uso da bicicleta. Para isso, foi realizada uma pesquisa de atitude que teve como base alguns fatores que influenciam na escolha da bicicleta como modo de transporte. Os resultados da pesquisa de atitude possibilitaram o desenvolvimento de uma escala de aceitabilidade ao uso da bicicleta, que indica quão favorável os indivíduos são em relação ao ciclismo. Além disso, a análise da pesquisa de atitude indica que os fatores a respeito dos quais houve maior concordância positiva entre os entrevistados são os que demonstram o ciclismo como um transporte barato e bom para a saúde. A escala de aceitabilidade ao ciclismo pode ser utilizada como um dos critérios para determinar a demanda potencial para o uso da bicicleta, além de acrescentar mais uma característica ao perfil dos entrevistados, auxiliando, assim, planejadores de transportes na promoção do uso da bicicleta.
\end{abstract}

\begin{abstract}
The objective of this paper is to investigate the perceptions of individuals about the use of bicycles. In order to do this, an attitude survey was performed based on a few factors that influence the choice of the bicycle as a mode of transport. The results of the attitude survey enabled the development of a scale of acceptability to bicycle use, which indicates how favorable people are towards cycling. In addition, analysis of the attitude survey indicates that factors on which there was a higher positive correlation among the respondents are the ones that show cycling as a mode of transport that is cheap and good for health. The scale of acceptability to cycling can be used as a criterion to determine the potential demand for bicycle use, besides adding another feature to the profile of respondents, thus, helping transport planners in promoting bicycle use.
\end{abstract}

\section{INTRODUÇÃO}

O incentivo ao transporte cicloviário faz parte da estratégia atual de planejamento urbano e de transportes, que tem como um dos objetivos reverter os problemas urbanos causados pela priorização do uso do automóvel, como congestionamentos, degradação da qualidade do ar e aumento do consumo energético. Outras vantagens do uso da bicicleta como modo de transporte incluem: maior equidade (entre membros da sociedade) na provisão de acesso a atividades, devido aos custos reduzidos desse modo de transporte e a possibilidade de promover um estilo de vida fisicamente mais ativo para a população.

O uso da bicicleta no Brasil teve uma expressiva expansão com a crise do petróleo em meados dos anos 70 do século passado, decaindo logo em seguida, nos anos 80 e início dos anos 90. Após 1994, houve uma nova perspectiva para esse modo de transporte devido à mudança das políticas públicas em alguns municípios (Affonso et al., 2003).

O Código de Trânsito Brasileiro (Lei no 9.503, de 23 de setembro de 1997) recolocou a bicicleta como veículo protegido no tráfego urbano, sendo dever dos municípios planejar e garantir a segurança da sua cir-

\footnotetext{
${ }^{1}$ Janice Kirner Providelo, Programa de Pós-Graduação em Engenharia Urbana, Universidade Federal de São Carlos, São Carlos, SP, Brasil. (e-mail: jkirner@gmail.com).

${ }^{2}$ Suely da Penha Sanches, Programa de Pós-Graduação em Engenharia Urbana, Universidade Federal de São Carlos, São CarIos, SP, Brasil. (e-mail: ssanches@ufscar.br).

Manuscrito recebido em 8/2/2010 e aprovado para publicação em 1/4/2010. Este artigo é parte de TRANSPORTES, volume XVIII, número 2, junho de 2010. ISSN: 2237-1346 (online).
}

culação. Além disso, o Código de Trânsito Brasileiro trouxe a perspectiva da utilização de receitas oriundas das multas e cobranças de serviços que antes eram realizados pelos Departamentos Estaduais de Trânsito, para aplicação na infra-estrutura viária (Brasil, 1997).

Segundo a ANTP, a frota brasileira de bicicletas era a maior da América do Sul, com 48 milhões de unidades em 2003, número que se destaca até no cenário mundial. No entanto, boa parte dessa frota não circulava, principalmente pela falta de segurança do ciclista inserido no trânsito violento das cidades grandes, e também pela falta de políticas de apoio a esse tipo de transporte (Affonso et al., 2003).

Recentemente, o Brasil apresentou um avanço no que se refere às políticas de apoio ao transporte cicloviário. Em 22 de setembro de 2005 foi assinada a portaria que criou o Programa Brasileiro de Mobilidade por Bicicleta - Bicicleta Brasil, com o objetivo de estimular governos municipais e estaduais a implantar e melhorar ações que podem promover a segurança de ciclistas nos deslocamentos urbanos, segundo o Ministério das Cidades (2005).

Assim, o programa afirma que a inclusão do transporte cicloviário nos sistemas de transporte existentes deve ser buscada em conjunto com o conceito de mobilidade urbana, que tem como foco a interseção entre quatro áreas: desenvolvimento urbano, sustentabilidade ambiental, inclusão social e democratização espacial. De acordo com o programa, a nova abordagem deve compreender a construção de facilidades para bicicletas, especialmente em áreas de expansão urbana (Ministério das Cidades, 2005). 
No entanto, para promover o uso da bicicleta, é necessário considerar os fatores que determinam a escolha desse modo de transporte e avaliar a percepção dos indivíduos acerca do ciclismo. Com isso, será possível determinar com mais exatidão as necessidades e anseios da demanda atual e potencial para o uso da bicicleta como modo de transporte e planejar infraestrutura apropriada para atendê-la.

Assim, como parte do desenvolvimento de um modelo de nível de serviço para bicicletas aplicável ao contexto das cidades brasileiras, uma pesquisa de atitude foi realizada com usuários e não usuários da bicicleta, para levantar a percepção dos indivíduos acerca do uso da bicicleta como modo de transporte. Questionários foram aplicados nas cidades paulistas de São Carlos e Rio Claro. A partir dos resultados da pesquisa de atitude, foi proposta uma escala de aceitabilidade ao ciclismo, que indica quão favoráveis os indivíduos são em relação ao ciclismo. Dessa forma, com base no estudo das percepções dos indivíduos acerca do ciclismo, o presente trabalho pretende auxiliar planejadores de transportes na promoção do uso da bicicleta.

\section{FATORES QUE INFLUENCIAM NA ESCOLHA DA BICICLETA COMO MODO DE TRANSPORTE}

A opção de um indivíduo por um modo de transporte é um processo complexo, que é influenciado por diversos fatores, como as características do indivíduo, da viagem que irá realizar e dos sistemas de transportes disponíveis (Pezzuto, 2002). A análise dos fatores que podem estimular e restringir o uso da bicicleta como modo de transporte foi foco de vários estudos.
O entendimento correto destes fatores é visto como um pré-requisito essencial para formular políticas que incluem a demanda latente para viagens de bicicleta (FHWA, 1992).

FHWA (1992) sugeriu a classificação dos fatores que influenciam na escolha modal dos indivíduos em dois grupos: fatores subjetivos e fatores objetivos. Os fatores subjetivos são menos relacionados com condições mensuráveis do que com a percepção pessoal e a interpretação das necessidades individuais, enquanto que os objetivos são fatores físicos que existem para todos, apesar de possuírem pesos que podem ser diferentes para cada indivíduo.

A Tabela 1 relaciona os fatores destacados por FHWA (1992). O comprimento da viagem, apesar de ser mensurável, foi classificado como um fator subjetivo, pois cada indivíduo tem sua própria percepção da distância aceitável para andar de bicicleta.

Entretanto, os fatores apresentados por FHWA (1992) foram levantados considerando as condições americanas da época. Também buscando identificar os fatores que influenciavam a opção de um indivíduo na escolha da bicicleta como modo de transporte, Pezzuto (2002) realizou uma pesquisa na cidade de Araçatuba, SP. O método utilizado para a coleta de dados foi a aplicação de questionários, que foram respondidos por usuários e não usuários de bicicleta. Para a análise dos resultados, os entrevistados foram divididos em três grupos: ciclistas (que utilizavam a bicicleta para viagens utilitárias), ciclistas casuais (que utilizavam a bicicleta para lazer e exercício) e não ciclistas.

Os resultados dessa pesquisa indicaram que a percepção em relação ao ciclismo e, portanto, aos fatores

Tabela 1. Fatores que influenciam na escolha modal dos indivíduos, segundo FHWA (1992)

\begin{tabular}{|c|c|c|}
\hline \multirow{11}{*}{ Fatores subjetivos } & & Comprimento da viagem \\
\hline & & Segurança no tráfego \\
\hline & & Conveniência \\
\hline & & Custo da viagem \\
\hline & & Valor atribuído ao tempo \\
\hline & & Valorização dos exercícios físicos \\
\hline & & Condições físicas \\
\hline & & Circunstâncias familiares \\
\hline & & Hábitos cotidianos \\
\hline & & Atitudes de valores sociais \\
\hline & & Aceitabilidade social \\
\hline \multirow{5}{*}{ Fatores objetivos } & \multirow{2}{*}{ Fatores ambientais } & Clima \\
\hline & & Topografia \\
\hline & \multirow{3}{*}{ Características da infraestrutura } & Infraestrutura adequada para bicicletas \\
\hline & & Acessibilidade e continuidade das rotas \\
\hline & & Alternativas de transporte \\
\hline
\end{tabular}


que interferem no uso da bicicleta, são diferentes para cada um desses grupos. No entanto, de forma geral, concluiu-se que os fatores que mais influenciam na escolha da bicicleta estavam relacionados aos aspectos de conforto e segurança, às vantagens oferecidas pelos modos motorizados e a valores e preferências pessoais (Pezzuto, 2002).

Segundo os resultados de uma pesquisa realizada por Dill e Voros (2007), as medidas de proximidade a ciclovias e ciclofaixas não foram associadas a maiores índices de utilização da bicicleta. Entretanto, os autores descobriram que percepções positivas sobre a disponibilidade de ciclovias foram associadas com o maior uso da bicicleta e com o desejo de aumentar a utilização desse modo de transporte.

Mais recentemente, Sener et al (2009) classificaram os fatores que podem influenciar na escolha da bicicleta como modo de transporte em três categorias: (1) características demográficas individuais ou domiciliares (como idade, gênero, etnia, posse de automóvel, e renda familiar); (2) atitudes individuais e percepções (como percepções de segurança e seguridade, tempo e custo percebidos, e atitudes relacionadas à participação em atividades físicas); e (3) características da vizinhança (como uso do solo, fatores ambientais, presença e tipos de facilidades para bicicletas, presença de chuveiros e armários no ambiente de trabalho, entre outros).

Sener et al. (2009) afirmam que, apesar de existir um interesse crescente em avaliar o comportamento dos ciclistas, há um número limitado de pesquisas sobre o efeito das atitudes individuais e percepções que influenciam o uso e a frequência de uso da bicicleta. Os autores realizaram uma pesquisa com ciclistas no estado americano do Texas, cujos resultados indicam que percepções em termos de fatores relacionados a segurança e qualidade tem um impacto na frequência do uso da bicicleta.

Assim sendo, com base em estudos anteriores e devido à sua importância no contexto das cidades brasileiras, alguns fatores foram escolhidos para serem utilizados em uma pesquisa de atitude, para levantar a percepção dos indivíduos acerca do ciclismo. São eles: segurança pessoal, esforço físico, aceitabilidade social, conforto térmico, infraestrutura específica para bicicletas, custo das viagens, distância das viagens, modo de transporte confortável, segurança para ciclistas, velocidade do ciclismo, valorização da saúde, preferência pessoal e estacionamento seguro para bicicletas.

\section{A PESQUISA}

O método escolhido para medir a percepção dos indivíduos foi a aplicação de questionários desenvolvidos com base na escala Likert. De acordo com Oppenheim (1999), a escala de Likert é uma das escalas disponíveis para avaliar atitudes, na qual os sujeitos localizam-se, para cada questão, em uma das seguintes posições: "concordo totalmente", "concordo em parte", "sem opinião", "discordo em parte" e "discordo totalmente". Treze questões foram formuladas com o objetivo de abordar os principais fatores que influenciam na escolha da bicicleta como modo de transporte.

Além da pesquisa de atitude, estruturada com base na escala Likert, os participantes também responderam uma série de questões voltadas ao levantamento do seu perfil: gênero, faixa etária, nível de escolaridade, se sabe ou não andar de bicicleta, se possui bicicleta em seu domicílio, que tipo de ciclista se considera, motivos de viagem para os quais utiliza bicicleta, tipos de infraestrutura utilizados para andar de bicicleta, e freqüência do uso da bicicleta.

A pesquisa foi realizada entre março e abril de 2009. No total, 451 questionários foram aplicados nas cidades paulistas de São Carlos e Rio Claro. Os locais de aplicação dos questionários foram escolhidos devido à disponibilidade dos alunos para a aplicação da pesquisa.

Além disso, tentou-se incluir diferentes perfis de participantes, principalmente no que diz respeito à faixa etária e às suas características socioeconômicas. Assim, foram incluídos locais de pesquisa que recebem alunos cursando o ensino fundamental e médio (como o Círculo de Amigos do Menino Patrulheiro "Dr. Marino da Costa Terra" e a Escola SENAI "Antonio Adolpho Lobbe", ambas em São Carlos), alunos que já finalizaram o ensino médio ou superior (Curso Técnico em Logística do SENAC São Carlos, PósGraduação em Engenharia Urbana da UFSCar, Graduação em Engenharia Civil da UFSCar e Graduação em Geografia da UNESP Rio Claro) e alunos de diferentes idades, cursando um programa para educação de jovens e adultos (Telecurso da Escola SESI São Carlos).

Os questionários foram preenchidos na presença da pesquisadora, e foram devolvidos logo em seguida. Assim, todos os questionários distribuídos foram devolvidos. No entanto, quatro questionários foram excluídos por apresentarem quatro ou mais respostas não válidas, ou seja, em branco ou com mais de uma resposta assinalada por questão. Portanto, as análises foram realizadas com base em 447 questionários respondidos.

\subsection{Resultados obtidos}

O perfil dos entrevistados está apresentado na Tabela 2. 
Tabela 2. Perfil dos entrevistados

\begin{tabular}{|c|c|c|c|}
\hline Questão & Resposta & Número & $\%$ \\
\hline \multirow{3}{*}{ Gênero } & masculino & 241 & 53,9 \\
\hline & feminino & 203 & 45,4 \\
\hline & resposta ausente & 3 & 0,7 \\
\hline \multirow{6}{*}{ Idade } & 13 а 17 & 252 & 56,4 \\
\hline & 18 a 24 & 130 & 29,1 \\
\hline & 25 a 29 & 36 & 8,1 \\
\hline & 30 а 39 & 12 & 2,7 \\
\hline & 40 a 49 & 12 & 2,7 \\
\hline & 50 ou mais & 5 & 1,1 \\
\hline \multirow{8}{*}{ Escolaridade } & fundamental incompleto & 84 & 18,8 \\
\hline & fundamental completo & 58 & 13,0 \\
\hline & médio incompleto & 126 & 28,2 \\
\hline & médio completo & 56 & 12,5 \\
\hline & superior incompleto & 98 & 21,9 \\
\hline & superior completo & 13 & 2,9 \\
\hline & pós graduação & 11 & 2,5 \\
\hline & resposta ausente & 1 & 0,2 \\
\hline \multirow{2}{*}{ Sabe andar de bicicleta } & $\operatorname{sim}$ & 440 & 98,4 \\
\hline & não & 7 & 1,6 \\
\hline \multirow{3}{*}{$\begin{array}{l}\text { Possiu bicicleta no } \\
\text { domicílio }\end{array}$} & $\operatorname{sim}$ & 343 & 76,7 \\
\hline & não & 102 & 22,8 \\
\hline & resposta ausente & 2 & 0,4 \\
\hline \multirow{4}{*}{ Tipo de ciclista } & pouco experiente & 168 & 37,6 \\
\hline & muito experiente & 198 & 44,3 \\
\hline & não ciclista & 80 & 17,9 \\
\hline & resposta ausente & 1 & 0,2 \\
\hline \multirow{7}{*}{$\begin{array}{c}\text { Motivos de viagem de } \\
\text { bicicleta }\end{array}$} & trabalho & 23 & 3,5 \\
\hline & escola & 88 & 13,4 \\
\hline & lazer & 288 & 43,8 \\
\hline & exercício & 159 & 24,2 \\
\hline & todos & 19 & 2,9 \\
\hline & outro & 1 & 0,2 \\
\hline & não utilizo & 79 & 12,0 \\
\hline \multirow{6}{*}{$\begin{array}{l}\text { Infraestrutura utilizada } \\
\text { para viagens de } \\
\text { bicicleta* }\end{array}$} & ruas pouco movimentadas & 300 & 40,1 \\
\hline & ruas mais movimentadas & 164 & 21,9 \\
\hline & calçadas & 65 & 8,7 \\
\hline & vias específicas para bicicletas & 71 & 9,5 \\
\hline & trilhas (off-road) & 65 & 8,7 \\
\hline & não utilizo & 83 & 11,1 \\
\hline \multirow{7}{*}{$\begin{array}{l}\text { Frequência semanal de } \\
\text { viagens de bicicleta }\end{array}$} & 1 dia & 29 & 6,5 \\
\hline & 2 a 4 dias & 78 & 17,4 \\
\hline & 5 a 6 dias & 57 & 12,8 \\
\hline & todos os dias & 52 & 11,6 \\
\hline & de vez em quando & 142 & 31,8 \\
\hline & não utilizo & 85 & 19,0 \\
\hline & resposta ausente & 4 & 0,9 \\
\hline
\end{tabular}

A maioria dos entrevistados tem de 13 a 17 anos e possui ensino médio incompleto ou escolaridade inferior. Esse resultado confirma a participação significativa de alunos jovens na pesquisa. Cabe enfatizar que os jovens constituem a parcela da população que mais utiliza a bicicleta, inclusive em países onde o seu uso é mais disseminado, como na Holanda, (Rietveld e Daniel, 2004). Além disso, os resultados de um estudo realizado nos Estados Unidos também indicaram que os jovens são mais inclinados à utilizar a bicicleta para fins utilitários (Dill e Voros, 2007). Portanto, o perfil dos participantes é considerado aceitável, pois a amostra da pesquisa é condizente com o perfil dos usuários em potencial da bicicleta como modo de transporte.

Homens e mulheres estão quase que igualmente representados na amostra. A grande maioria dos entrevistados possui bicicleta em seu domicílio e sabe andar de bicicleta. Apesar de não utilizarem a bicicleta 
semanalmente, mas apenas "de vez em quando", a maior parte dos entrevistados considera-se um ciclista experiente. Nesse aspecto, cabe destacar que o fato de um indivíduo saber andar de bicicleta não faz dele um ciclista. Considera-se que ciclistas são aqueles que utilizam a bicicleta (com menor ou maior frequência e para finalidades diversas), mas não inclui aqueles que aprenderam a andar de bicicleta na infância e mais tarde não continuaram a usar a bicicleta. Desta forma, foram obtidas respostas "sabe andar de bicicleta" e "não ciclista” do mesmo indivíduo.

A grande maioria dos entrevistados afirmou utilizar a bicicleta por motivo de lazer e exercício. Quanto à infraestrutura utilizada para viagens de bicicleta, as vias urbanas, tanto as mais movimentadas quanto as menos movimentadas, foram bastante indicadas pelos entrevistados. Um número menor de entrevistados afirmou utilizar vias específicas para bicicletas, talvez pela escassez desse tipo de infraestrutura nas cidades onde foram aplicados os questionários. Algumas pessoas ainda indicaram utilizar calçadas para andar de bicicleta, apesar do Código de Trânsito Brasileiro, no Art. 59, somente permitir a circulação de bicicletas no passeio se autorizado e devidamente sinalizado pelo órgão ou entidade com circunscrição (Brasil, 1997).

Os resultados da pesquisa de atitude, estruturada com base na escala Likert, são apresentados na Tabela 3. Cada uma das afirmações avaliadas pelos participantes está relacionada com um dos fatores que influenciam na escolha da bicicleta como modo de transporte.

\subsection{Nível de concordância com as afirmações}

Os dados coletados através da escala Likert são em forma de categorias ordenadas (escala ordinal), que

Tabela 3. Resultados da pesquisa de atitude

\begin{tabular}{|c|c|c|c|c|c|c|}
\hline \multirow[b]{2}{*}{ Fatores } & \multirow[b]{2}{*}{ Afirmações } & \multicolumn{5}{|c|}{ Respostas (\%) } \\
\hline & & $\begin{array}{c}\text { Concordo } \\
\text { totalmente }\end{array}$ & $\begin{array}{l}\text { Concordo } \\
\text { em parte }\end{array}$ & $\begin{array}{c}\text { Sem } \\
\text { opinião }\end{array}$ & $\begin{array}{l}\text { Discordo } \\
\text { em parte }\end{array}$ & $\begin{array}{c}\text { Discordo } \\
\text { totalmente }\end{array}$ \\
\hline $\begin{array}{l}\text { Possibilidade de } \\
\text { agressões }\end{array}$ & $\begin{array}{l}\text { Quem anda de bicicleta corre } \\
\text { risco de ser assaltado. }\end{array}$ & 33,8 & 38,9 & 11,4 & 12,1 & 3,8 \\
\hline Exige esforço físico & $\begin{array}{l}\text { Andar de bicicleta é muito } \\
\text { cansativo. }\end{array}$ & 14,3 & 40,9 & 5,4 & 25,5 & 13,9 \\
\hline $\begin{array}{l}\text { Bem aceito } \\
\text { socialmente }\end{array}$ & $\begin{array}{l}\text { A maioria das pessoas que } \\
\text { eu conheço aprova (ou a } \\
\text { provaria) que eu use a } \\
\text { bicicleta para trabalhar ou } \\
\text { ir à escola. }\end{array}$ & 37,1 & 30,4 & 14,8 & 10,1 & 7,6 \\
\hline $\begin{array}{l}\text { Sol e calor } \\
\text { incomodam }\end{array}$ & $\begin{array}{l}\text { O sol e o calor são motivos } \\
\text { para não se usar a bicicleta. }\end{array}$ & 30,9 & 34,2 & 4,5 & 17,4 & 13,0 \\
\hline Falta infra-estrutura & $\begin{array}{l}\text { Se houvesse uma faixa } \\
\text { reservada para ciclistas nas } \\
\text { ruas eu andaria (ou andaria } \\
\text { mais) de bicicleta. }\end{array}$ & 67,1 & 20,1 & 5,4 & 3,1 & 4,3 \\
\hline Transporte barato & $\begin{array}{l}\text { Andar de bicicleta é mais } \\
\text { barato do que andar de carro, } \\
\text { ônibus ou moto. }\end{array}$ & 85,5 & 9,4 & 2,7 & 0,9 & 1,6 \\
\hline $\begin{array}{l}\text { Ruim para viagens } \\
\text { longas }\end{array}$ & $\begin{array}{l}\text { Não uso a bicicleta porque } \\
\text { os lugares que freqüento } \\
\text { ficam muito longe da minha } \\
\text { casa. }\end{array}$ & 17,9 & 25,3 & 15,4 & 18,3 & 23,0 \\
\hline Desconfortável & $\begin{array}{l}\text { Prefiro andar de carro/ } \\
\text { ônibus/moto porque é mais } \\
\text { confortável do que a } \\
\text { bicicleta. }\end{array}$ & 32,4 & 32,2 & 8,5 & 14,1 & 12,8 \\
\hline Falta segurança & $\begin{array}{l}\text { Se as ruas fossem mais } \\
\text { seguras para os ciclistas, eu } \\
\text { andaria (ou andaria mais) de } \\
\text { bicicleta. }\end{array}$ & 56,4 & 24,2 & 8,7 & 6,0 & 4,7 \\
\hline Muito lento & $\begin{array}{l}\text { A bicicleta é um transporte } \\
\text { muito lento. }\end{array}$ & 10,7 & 40,9 & 7,6 & 27,3 & 13,4 \\
\hline Bom para saúde & $\begin{array}{l}\text { Andar de bicicleta faz bem } \\
\text { para a saúde. }\end{array}$ & 85,9 & 9,2 & 1,8 & 1,6 & 1,6 \\
\hline $\begin{array}{l}\text { Não gosto de } \\
\text { bicicleta }\end{array}$ & $\begin{array}{l}\text { Não ando de bicicleta porque } \\
\text { não gosto. }\end{array}$ & 5,6 & 6,0 & 13,4 & 13,4 & 61,5 \\
\hline $\begin{array}{l}\text { Falta } \\
\text { estacionamento }\end{array}$ & $\begin{array}{l}\text { Eu usaria (ou usaria mais) a } \\
\text { bicicleta se existissem } \\
\text { estacionamentos seguros no } \\
\text { meu trabalho/escola. }\end{array}$ & 45,9 & 22,1 & 14,8 & 8,9 & 8,3 \\
\hline
\end{tabular}


permitem que se conheça a ordem de importância que o entrevistado atribui aos fatores que fazem parte da pesquisa de atitude. No entanto, não é possível saber diretamente quanto um fator é mais importante que o outro, ou seja, qual é o peso atribuído a cada um dos fatores. A distância entre dois fatores consecutivos é desconhecida e, geralmente, não é uniforme. Assim, utilizou-se o Método dos Intervalos Sucessivos para transformar dados categóricos em uma escala intervalar, que permite avaliar a importância relativa entre os fatores.

O Método dos Intervalos Sucessivos considera que a variável subjacente à escolha dos indivíduos segue uma distribuição de probabilidade normal. Desta forma, é possível estimar os valores das categorias a partir das frequências observadas, sendo que as categorias observadas correspondem a diferentes segmentos sob uma curva normal padrão. Esse procedimento foi descrito em detalhe por Providelo e Sanches (2010).

Os resultados da análise através do Método dos Intervalos Sucessivos são mostrados na Figura 1, em uma escala de 0 a 1 . Quanto maior o valor, maior a concordância.

Considerando-se os resultados mostrados na Figura 1 , os fatores a respeito dos quais houve maior concordância positiva são os relacionados ao custo das viagens ("Andar de bicicleta é mais barato do que andar de carro, ônibus ou moto”) e à saúde (“Andar de bicicleta faz bem para a saúde”). Também a infraestrutura específica para bicicletas ("Se houvesse uma faixa reservada para ciclistas nas ruas eu andaria (ou andaria mais) de bicicleta”) teve grande concordância por parte dos entrevistados.

\subsection{Escala de aceitabilidade ao uso da bicicleta como modo de transporte}

Além de avaliar individualmente cada um dos fatores abordados na pesquisa de atitude, a escala Likert também permite o cálculo de uma somatória (Oppenheim, 1999). No caso da presente pesquisa, a somatória in- dica quão favorável cada um dos participantes é em relação ao uso da bicicleta como modo de transporte. Assim, tal somatória pode ser avaliada como uma escala de aceitabilidade ao uso da bicicleta.

A concordância ou discordância de um indivíduo com cada uma das afirmações do questionário depende, em parte, de sua percepção com relação ao ciclismo e, em parte, de alguns outros aspectos da afirmação ou do indivíduo. Ou seja, a resposta de um indivíduo para uma afirmação específica pode ser dividida em duas parcelas: uma que reflete o valor real atribuído pelo entrevistado àquela afirmação e uma que corresponde a um erro aleatório.

Assim, para que uma escala seja confiável é necessário avaliar sua consistência interna (uma medida baseada na correlação entre os itens). Esta medida avalia se os diferentes itens que foram propostos para medir um conceito geral produzem as mesmas avaliações. Por exemplo, se um respondente expressou concordância com as afirmações "Eu gosto de andar de bicicleta" e "Eu gostava de andar de bicicleta quando criança", e discordância com a afirmação "Eu odeio bicicletas”, isto é uma indicação de que a consistência interna é boa.

A consistência interna da escala é geralmente medida com o Alfa de Cronbach, uma estatística calculada a partir das correlações entre os itens. O valor do coeficiente $\alpha$ pode variar entre 0 (indicando um item não confiável) e 1 (indicando um item perfeitamente confiável). Uma regra geralmente aceita é que valores de alfa próximos de ou maiores que 0,6 indicam uma confiabilidade aceitável, e valores maiores muito altos (0,95 ou maiores) não são, necessariamente desejáveis, porque indicam que os itens podem ser totalmente redundantes.

A análise do coeficiente $\alpha$ também permite verificar se cada um dos itens individuais é consistente com a escala como um todo. Caso um item não seja consistente, deve ser excluído das análises. Na prática, são necessárias várias rodadas de inclusão e eliminação de

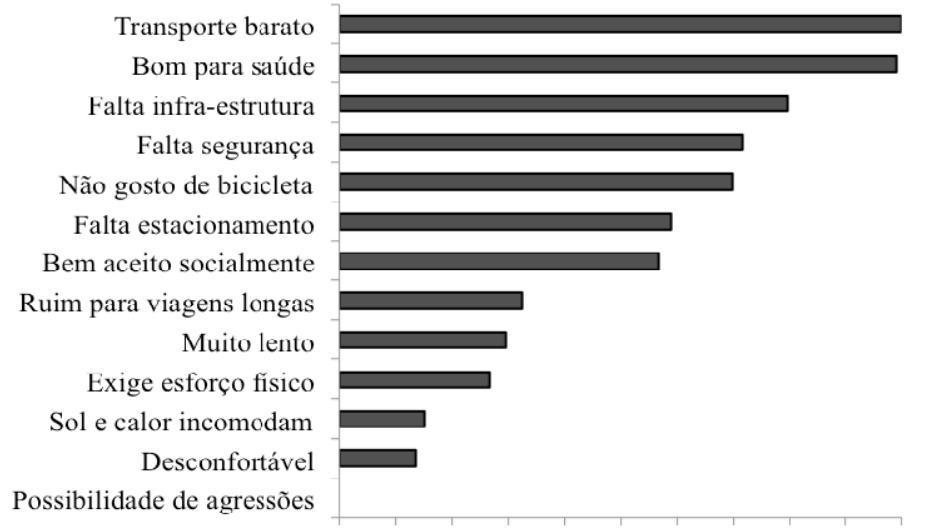

$\begin{array}{llllllllllll}0.00 & 0.10 & 0.20 & 0.30 & 0.40 & 0.50 & 0.60 & 0.70 & 0.80 & 0.90 & 1.00\end{array}$

Figura 1. Nível de concordância com as afirmações 
itens até se chegar a um conjunto final que se constitua em uma escala confiável (Statsoft, 2002 apud Pezzuto, 2002).

A Tabela 4 apresenta os itens finais que foram mantidos na escala de aceitabilidade ao uso da bicicleta. Foram mantidos aqueles itens que apresentam correlação com a escala total maior que 0,30 . A coluna da direita mostra a consistência interna da escala se o item fosse excluído.

Tabela 4. Itens finais da escala de aceitabilidade ao uso de bicicleta

\begin{tabular}{ccc}
\hline Consistência interna da escala ( $\boldsymbol{\alpha}$ de Cronbach) $=\mathbf{0 , 5 7 2}$ \\
\hline & $\begin{array}{c}\text { Correlação entre } \\
\text { o item e a }\end{array}$ & $\begin{array}{c}\text { a se o item for } \\
\text { eliminado }\end{array}$ \\
& escala total & \\
\hline Exige esforço físico & 0,33 & 0,528 \\
Falta infra-estrutura & 0,307 & 0,538 \\
Desconfortável & 0,344 & 0,524 \\
Muito lento & 0,303 & 0,535 \\
Não gosto de bicicleta & 0,376 & 0,52 \\
\hline
\end{tabular}

Os itens selecionados para definir a escala de aceitabilidade ao uso da bicicleta podem ser vistos como fatores frequentemente citados como desvantagens ao uso da bicicleta, caracterizando, muitas vezes, uma imagem preconceituosa do modo de transporte. Assim, considera-se que a avaliação da percepção acerca destes itens será adequada para medir o nível de aceitabilidade dos indivíduos em relação ao ciclismo.

Após selecionar os itens da escala, o próximo passo foi o cálculo da somatória das notas dadas na escala Likert para cada um dos entrevistados. Para o cálculo da somatória, considerou-se que um resultado alto significaria uma atitude favorável ao uso da bicicleta. Assim, o item com conteúdo positivo em relação ao uso da bicicleta (falta infraestrutura) foi classificado como: "concordo totalmente" $=5$ e "discordo totalmente" $=1$. Este item foi considerado conteúdo positivo em relação ao uso da bicicleta, pois indica que o indivíduo demonstra vontade de andar de bicicleta caso a situação corrente seja alterada.

Ao contrário, as questões com conteúdo negativo em relação ao uso da bicicleta (exige esforço físico, desconfortável, muito lento, não gosto de bicicleta) foram classificadas como: "concordo totalmente" $=1$ e "discordo totalmente" $=5$. Como foram mantidos cinco itens, o resultado máximo esperado seria 25 e o resultado mínimo esperado seria 5 (média igual a 15).

A estatística descritiva dos resultados da pesquisa indica que o menor valor obtido foi 5, e o valor máximo foi 25 , com média igual a 16,79 . Como este valor está um pouco acima da média da escala (15) conclui-se que, de maneira geral, os entrevistados mostraram uma tendência de aceitabilidade ao ciclismo.

Pela distribuição de freqüência das respostas (Figu- ra 2), pode-se verificar que a distribuição é aproximadamente normal. Portanto, a maior parte dos entrevistados coloca-se em uma posição intermediária com relação ao uso da bicicleta, ou seja, entre favorável e desfavorável. Assim, foi considerado que a parte central da figura é caracterizada pelos "indiferentes" em relação ao uso da bicicleta como modo de transporte.

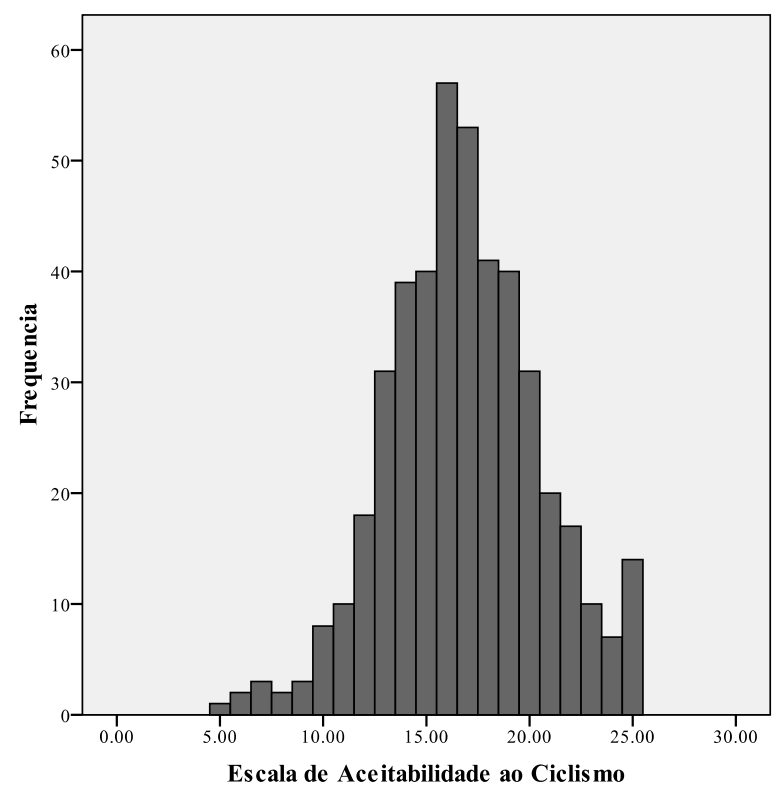

Figura 2. Distribuição de frequência das respostas

Um procedimento de agrupamento (K-means clustering) mostrou que os respondentes poderiam ser divididos em três grupos, com base na escala de aceitabilidade ao ciclismo (com nível de confiança de 95\%). O grupo 1 inclui os indivíduos que são favoráveis ao uso da bicicleta, de acordo com a escala de aceitabilidade; o grupo 2 inclui aqueles que são considerados indiferentes ao ciclismo; e o grupo 3 é definido pelos respondentes que não são favoráveis ao ciclismo. A Tabela 5 mostra as características dos grupos.

De acordo com os resultados da Tabela 5, mais da metade dos entrevistados (51\%) foram classificados como indiferentes ao uso da bicicleta como modo de transporte. O número de entrevistados favoráveis e não favoráveis ao uso da bicicleta, por sua vez, corresponderam a $17 \%$ e $31 \%$, respectivamente. Os resultados indicam, portanto, que apesar da minoria dos entrevistados serem efetivamente favoráveis ao uso da bicicleta, há uma grande parcela de entrevistados (indiferentes) que pode ser convencida a utilizar a bicicleta.

Utilizando a escala de aceitabilidade ao ciclismo foi realizada uma ANOVA com o objetivo de verificar se existe diferença de nível de aceitabilidade ao ciclismo entre os diferentes grupos de entrevistados (em função de suas características). A Tabela 6 mostra as características que apresentaram diferenças estatisticamente significativas (com 95\% de confiança).

Verifica-se que existe diferença significativa entre 
Tabela 5. Comparação entre os três grupos

\begin{tabular}{ccccc}
\hline Critério & Grupos & $\begin{array}{c}\text { Número de } \\
\text { casos }\end{array}$ & $\begin{array}{c}\text { Média do } \\
\text { Critério }\end{array}$ & Desvio Padrão \\
\hline \multirow{3}{*}{ Aceitabilidade } & 1 (favorável) & 78 & 21.02 & 1.969 \\
& 2 (indiferente) & 230 & 16.07 & 1.341 \\
\hline
\end{tabular}

Tabela 6. Comparação das médias de aceitabilidade ao ciclismo

\begin{tabular}{lllc}
\hline Característica & Grupo & Média & p (95\%) \\
\hline \multirow{2}{*}{ Gênero } & Masculino & 17,1411 & \multirow{2}{*}{0,048} \\
& Feminino & 16,4433 & \\
\hline \multirow{3}{*}{ Idade } & 13 a 17 anos & 16,4048 & \\
& 18 a 24 anos & 17,2154 & \\
& 25 a 29 anos & 16,8333 & \multirow{2}{*}{0,014} \\
& 30 a 39 anos & 17,0833 & \\
Tipo de ciclista & 40 a 49 anos & 18,2500 & \\
& 50 anos ou mais & 21,4000 & \\
& Pouco experiente & 16,5238 & \\
& Muito experiente & 17,6465 & 0,000 \\
& Não ciclista & 15,2875 & \\
& 1 dia por semana & 15,5862 & \\
& 2 a 3 dias por semana & 17,5641 & \\
Frequência de uso & 4 a 5 dias por semana & 18,0702 & \multirow{2}{*}{0,000} \\
& Todos os dias & 17,5385 & \\
& De vez em quando & 16,8592 & \\
& Não utilizo & 15,1765 & \\
\hline
\end{tabular}

homens e mulheres com relação à aceitabilidade ao ciclismo, sendo que os homens são mais favoráveis ao uso da bicicleta.

Quanto à idade dos entrevistados, percebe-se que os mais velhos são mais favoráveis ao ciclismo do que os mais jovens, com exceção para a faixa etária que vai dos 18 aos 24 anos. A faixa dos 18 aos 24 anos corresponde, em sua maioria, aos universitários entrevistados. De forma geral, este resultado pode indicar uma mudança no status deste modo de transporte entre as gerações. No entanto, tal diferença de aceitabilidade entre as faixas etárias pode estar relacionada a outras características do perfil dos indivíduos mais velhos. Desta forma, recomenda-se que as razões para as diferenças na aceitabilidade ao ciclismo nas diferentes faixas etárias sejam investigadas mais profundamente.

Em relação ao tipo de ciclista, os ciclistas que se consideram muito experientes são mais favoráveis e os não ciclistas os menos favoráveis. Do mesmo modo, os indivíduos que utilizam a bicicleta mais frequentemente apresentam uma maior aceitabilidade ao ciclismo.

\section{CONSIDERAÇÕES FINAIS}

Para promover o uso da bicicleta, é necessário considerar os fatores que determinam a escolha desse modo de transporte e avaliar a percepção dos indivíduos acerca do ciclismo. Assim, uma pesquisa de atitude foi realizada nas cidades de São Carlos e Rio Claro, com usuários e não usuários da bicicleta, para levantar a percepção dos indivíduos acerca do uso da bicicleta como modo de transporte.

A análise da pesquisa de atitude indica que os fatores a respeito dos quais houve maior concordância positiva entre os entrevistados são os que demonstram o ciclismo como um transporte barato e bom para a saúde.

A partir dos resultados da pesquisa de atitude, foi proposta uma escala de aceitabilidade ao uso da bicicleta, que indica quão favorável os indivíduos são em relação ao ciclismo. Foram utilizados cinco fatores (itens). De acordo com a escala proposta, os entrevistados foram classificados em "favorável", "indiferente" e "não favorável" ao uso da bicicleta. A grande maioria dos entrevistados é indiferente ao uso da bicicleta, o que demonstra que existe uma grande parcela de indivíduos que pode ser convencida a utilizar a bicicleta.

A escala de aceitabilidade ao uso da bicicleta pode ser utilizada como um dos critérios para determinar a demanda potencial para o uso da bicicleta como modo de transporte, juntamente com outras análises, como por exemplo, a exclusão dos participantes que possuem alguma restrição física ao uso da bicicleta e a análise do comprimento das viagens realizadas pelos participantes e exclusão das viagens longas.

Esta escala está sendo utilizada em uma pesquisa, ainda em desenvolvimento, visando acrescentar mais uma característica ao perfil dos entrevistados: o nível de aceitabilidade ao ciclismo. Tal medida pode também ser comparada com as demais características dos entrevistados. Verificou-se que existe diferença significativa com relação à aceitabilidade ao ciclismo entre 
os grupos separados de acordo com as seguintes características: gênero (homens são mais favoráveis), idade (indivíduos mais velhos são mais favoráveis), tipo de ciclista (ciclistas que se consideram muito experientes são mais favoráveis e não ciclistas menos favoráveis), e frequência de uso da bicicleta (indivíduos que utilizam a bicicleta mais frequentemente são mais favoráveis).

Dessa forma, a partir do estudo das percepções dos indivíduos acerca do uso da bicicleta como modo de transporte, o presente trabalho pretende auxiliar planejadores de transportes na promoção do uso da bicicleta.

\section{AGRADECIMENTOS}

As autoras agradecem à FAPESP - Fundação de Amparo à Pesquisa do Estado de São Paulo pelo apoio financeiro, e aos participantes da pesquisa, pela colaboração. Esta pesquisa teve o apoio do Cycling Academic Network (CAN), parte do Bicycle Partnership Program do Interface for Cycling Expertise (I-CE), Utrecht, Holanda.

\section{REFERÊNCIAS BIBLIOGRÁFICAS}

Affonso, N. S.; Badini, C.; Gouvea, F. (2003) Mobilidade e Cidadania. São Paulo, ANTP.

Brasil (1997) Ministério da Justiça. Lei No 9.503, de 23 de setembro de 1997. Diário Oficial da República Federativa do Brasil, Brasília, 24 de setembro 1997. p. 21201.

Dill, J. e Voros, K. (2007) Factors Affecting Bicycling Demand: Initial Survey Findings from the Portland. Oregon Region. Transportation Research Record: Journal of the Transportation Research Board, vol. 2031, p. 9-17.

FHWA (2002) Reasons Why Bicycling and Walking Are and Are Not Being Used More Extensively as Travel Modes. Federal Highway Administration, US Department of Transportation McLean, VA.

Ministério das Cidades (2005) Ministério das Cidades vai investir R\$62 milhões no Programa Brasileiro de Mobilidade por Bicicleta - Bicicleta Brasil. Disponível em: http://www.cidades.gov.br. Acesso em: 10/12/2005.

Oppenheim, A. N. (1999) Questionnaire Design, Interviewing and Attitude Measurement. Pinter, London.

Pezzuto, C. C. (2002) Fatores que Influenciam o Uso da Bicicleta, Dissertação (Mestrado em Engenharia Urbana) - Centro de Ciências Exatas, Universidade Federal de São Carlos, São Carlos.

Providelo, J. K. e Sanches, S. P. (2010) Roadway and Traffic Characteristics for Bicycling. Proceedings WCTR - World Conference on Transport Research, Lisboa, Portugal.

Rietveld, P. e Daniel, V. (2004) Determinants of Bicycle Use: Do Municipal Policies Matter? Transportation Research Part A: Policy and Practice, vol. 38, no. 7, p. 531-550.

Sener, I. N., Eluru, N., Bhat, C. R. (2009) Analysis of Bicyclists and Bicycling Characteristics: Who, Why, and How Much Are They Bicycling? TRB 88th Annual Meeting Compendium of Papers DVD, Transportation Research Board, Washington, D.C. 